\title{
Exclusión social y abstención electoral en barrios de alta población gitana
}

\author{
Social Exclusion and Electoral Abstention in Neighborhoods with a \\ High Romá Population \\ Manuel Trujillo-Carmona
}

IESA-CSIC

\section{RESUMEN}

En algunos estudios se ha constatado que la población gitana tiene unas tasas extremadamente bajas de participación en elecciones, con resultados tomados de las encuestas FOESSA. Pero aparte de esta fuente no tenemos otras encuestas que analicen con más detalle los factores que intervienen en este hecho. En este artículo se analizan los resultados de participación electoral en las últimas elecciones generales. Se analiza si los barrios de más concentración de población gitana son los que mayor abstención electoral registran. La identificación de esos barrios, imposible de realizar a través de censos sin identificaciones étnicas, se realiza a través del "Mapa de Población y Vivienda Gitana".

Se constata que, efectivamente, los barrios con mayor presencia de población gitana son los que presentan mayor abstención electoral. Pero se da un paso más y se analiza la posible influencia de la renta de los hogares en esa relación. Se constata también que las secciones con mayor presencia de población gitana son las que reúnen más porcentaje de hogares en riesgo de pobreza, lo que lleva a plantear si la baja participación en elecciones en esos barrios podría explicarse en función de la renta. Mediante un análisis lineal se obtiene que el porcentaje de hogares en riesgo de pobreza explica la mayor parte de la diferencia de participación política electoral entre los hogares con población gitana y los demás hogares, si bien no toda. La conclusión por tanto es que en los barrios con mayor población gitana se vota menos que en el resto, pero debido a la alta proporción de hogares pobres. 
PALABRAS CLAVE: Población gitana, desigualdad electoral, participación política electoral, abstención

\section{ABSTRACT}

Some studies have confirmed that gypsy population have an extremely low participation rate in elections. The results have been taken from FOESSA surveys. But other than this source we do not have other surveys which analyse in morte detail the factors that cause this fact. This article is an analysis of the participation in the last general elections, to see whether in those neighbourhoods with a higher rate of gypsy population there is also more abstention. It is impossible to identify those neighbourhoods with the population census, for there is no ethnic identification, and therefore the Gypsy population and housing map is used.

It is confirmed that those neighbourhoods with a higher presence of gypsy population also show a higher abstention. But we take a step further and analyse the potential influence of home income in this relation. It is also confirmed that those sections with a higher presence of gypsy population are the ones with a higher rate of homes in risk of poverty, and the approach is therefore whether the low participation in elections in those neighbourhoods could be incomerelated. A linear analysis shows that the rate of homes in risk of poverty explains most of the political participation difference between homes with gypsy population and the rest, but not all of it. Therefore the conclusion is that in neighbourhoods with more gypsy population people vote less. This is mostly due not to the fact of there being more gypsy population, but rather to the higher rate of poor households.

KEY WORDS: Romá, social exclusion, electoral political participation, abstention

\section{INTRODUCCIÓN}

El efecto de la desigualdad en la participación política es un asunto con bastante solera en la investigación, con resultados claros en cuanto a la falta de participación política en acciones distintas del voto, pero con controversia sobre si en España la desigualdad afecta a la participación en elecciones. 
Los trabajos realizados con encuestas no muestran una gran desigualdad en el voto, mientras que los realizados estudiando la distribución del voto real según las características del barrio o la sección sí encuentran unos claros patrones de desigualdad. Esto puede ocurrir por los problemas de medición en encuestas del recuerdo de voto, y también de los ingresos. Pero sobre todo porque, como se verá más adelante, la relación entre pobreza y abstención no se refleja apenas en los datos a nivel nacional, sino que hay que bajar a escala local para encontrarlos, cosa que no se puede hacer con una encuesta.

La desigualdad en la participación electoral, si existe, puede tener como consecuencia que las políticas que se realizan olviden a esos colectivos que votan poco (McElwee 2015). Por ello es muy relevante estudiar a quien le afecta y con qué condicionantes.

Para la población gitana está constatado su escaso asociacionismo (Méndez 2005), pero sobre su participación en elecciones solo existen los datos de las encuestas FOESSA. Con esos datos en anteriores trabajos (Trujillo y Gómez 2011 y 2019) hemos encontrado que la población gitana tiene unas tasas muy bajas de participación en elecciones: por debajo de la media de población española de su misma situación educativa o económica. Esa situación no es específica de España. En otros países de Europa también se constata la falta de participación de las comunidades romà (Barany 2001).

La medición de la participación en elecciones de la población gitana española tiene dos obstáculos adicionales, que pueden explicar el déficit de estudios sobre la temática. Por un lado, las encuestas oficiales españolas y particularmente las que habitualmente se realizan sobre asuntos políticos, como las del CIS, nunca preguntan sobre la etnia del entrevistado. Resulta por tanto muy difícil obtener datos directos de encuesta sobre la cuestión.

La otra vía que se está abriendo paso para estudiar la participación en elecciones, utilizar los datos de resultados electorales por secciones, es la que se utiliza en este artículo. Tiene la dificultad de que en los censos de población tampoco se pregunta por la etnia, por lo que a priori no se sabe en qué secciones se ubica la población gitana ${ }^{1}$. Este obstáculo para este artículo se salva con la utilización de

${ }^{1}$ La producción de datos de carácter étnico provoca un intenso debate sobre su pertinencia y necesidad ética y política en conexión con cuestiones más metodológicas acerca de la validez y la precisión en la medición de variables como la "identidad étnica". Por una parte, desde diversas instituciones internacionales se insta a producir y recoger datos que visibilicen las situaciones de discriminación y exclusión por motivos étnicos (Makkonen, 2016) para mejorar el alcance y 
los datos del Mapa de Vivienda Gitana (Fundación Secretariado Gitano y Daleph 2016).

El problema final es delimitar si la etnia es la causa de la baja participación, o si solo es un factor que acompaña a la principal variable que se encuentra correlacionada con la misma: la pobreza. Dado que la población gitana, y especialmente la que vive concentrada en barrios, está muy afectada por la pobreza (FSG, 2019), habría que delimitar si la baja participación en esos barrios se debe a la influencia de la etnia o a la pobreza.

En este artículo, en primer lugar, se revisa el estado de conocimiento sobre la desigualdad en la participación electoral en España y en la participación política de la población gitana. Se explica la metodología del análisis y los criterios para ubicar los barrios con concentración de población gitana (en adelante, BCPG). A continuación, se estudian los datos de participación en las últimas elecciones por sección, y su relación con la renta. Posteriormente se estudian los datos de participación en los BCPG y se analiza si la baja participación encontrada se puede explicar por sus datos de ingresos.

\section{LA DESIGUALDAD EN LA PARTICIPACIÓN ELECTORAL Y SUS CONSECUENCIAS}

\section{LA DESIGUALDAD EN LA PARTICIPACIÓN ELECTORAL}

Aunque son muchos los factores que intervienen en la participación electoral, se pueden considerar tres centrales: los recursos de los electores, la movilización estratégica llevada a cabo por las élites políticas, y las instituciones políticoelectorales que afectan a las decisiones y movilización de los electores (Boix y Riba 2000).

Por recursos se entiende los elementos que los electores emplean en el proceso de decisión y de participación política: conocimiento y educación, medios materiales y tiempo. Dado que la decisión de votar requiere una inversión de

efectividad de las políticas de atención e inclusión de los colectivos más vulnerables. Sin embargo, otras posturas -provenientes de contextos donde se han producido abusos o crímenes a raíz del recuento e identificación de minorías étnicas, como, por ejemplo, por el nazismo en Alemania- se muestran críticas con la producción de este tipo de datos por sus efectos estigmatizadores y excluyentes y, también, por el riesgo de manipulación desde planteamientos xenófobos y racistas (Reuss y Mack 2019). 
recursos, se concluye que aquellas personas con más tiempo, dinero e información tienen una mayor propensión a participar. Además, aquellos que tienen más preocupación y experiencia tienden a pensar que su voto es más útil.

La segunda explicación es la denominada de movilización estratégica, que examina en qué medida la intervención política consigue movilizar el voto. A mayor movilización más incentivos para participar. La tercera explicación tiene que ver con todo lo relacionado con el sistema electoral y los mecanismos relacionados con la forma de votar. En este artículo solo vamos a analizar la posible influencia de los recursos en la participación de los gitanos en las elecciones, pero no es de descartar que también la falta de movilización estratégica de los partidos tenga su importancia a la hora de explicar la baja participación. De acuerdo con esta categorización, diversos estudios encuentran que la falta de recursos está asociada a la falta de participación (Blais 2000; Whiteley et al., 2001). La tenencia o no de recursos, es un exponente de la desigualdad social, que se puede medir de diversas formas. En Caínzos y Voces (2010: 6), basándose en literatura referida a Estados Unidos, Gran Bretaña y otros países se concluye:

Independientemente de cómo sea medida la clase social, las investigaciones muestran consistentemente que personas de una clase social más alta es más probable que participen en política que personas de clase social más baja". "Estos comportamientos diferenciales han sido explicados por una amplia variedad de mecanismos causales, como desigualdad de recursos, diferentes normas cívicas, diferentes redes sociales, y diferentes prácticas de reclutamiento por organizaciones políticas.

En este mismo artículo se analizan datos de la Encuesta Social Europea destacándose para los países analizados importantes diferencias en participación política según la clase social y el nivel educativo. Pero se encuentra que estas diferencias son acusadas en la participación no electoral, pero son pequeñas en la participación electoral.

\section{CONSECUENCIAS DE LA DESIGUALDAD EN LA PARTICIPACIÓN ELECTORAL}

¿Cuáles son las consecuencias de la desigualdad en la participación electoral? Como señala Lijphart (1997), "quien vota, y quien no vota, tiene importantes consecuencias para quien es elegido, y para el contenido de políticas públicas". Allí donde es menor la desigualdad en la participación, donde votan más los 
pobres, hay una mayor redistribución, como confirman Mahler, Jesuit y Paradowski (2013) en un estudio realizado con datos de 14 países (no estando España entre ellos) en el cual medían la desigualdad en la participación electoral con la Encuesta Social Europea (ESS) y el Estudio Comparativo de Sistemas Electorales (CSES), y la redistribución con la base de datos LIS.

Los representantes pueden dar la espalda a las preferencias de los más pobres porque nunca entran en el sistema, ni tampoco están esperando a la salida del ciclo electoral para castigar o premiar a los que le dieron su voto. Ni mandan, ni controlan, desaparecen los incentivos para que los partidos políticos recojan sus intereses en sus programas y sus políticas (Trujillo y Gómez 2019).

\section{DESIGUALDAD EN LA PARTICIPACIÓN EN ELECCIONES EN ESPAÑA}

No hay muchos estudios sobre la desigualdad en la participación política en España, y a veces sus resultados son contradictorios. En Gallego (2007), con datos de la Encuesta Social Europea a nivel agregado se encuentra que hay diferencias importantes en la participación política en general y electoral en particular para las variables de renta, nivel educativo, situación laboral y clase social. Sin embargo, a nivel nacional en Gallego (2010) se encuentra que el nivel educativo tiene una influencia escasa, llegándose en Gallego (2013) a decir que el nivel educativo no influye en la participación, con lo que se argumenta que no hay diferencia según la posición social en la participación. Bermúdez y Ferrer (2014) concluyen más claramente que estar en paro o tener bajo nivel educativo sí influye en ser abstencionista habitual. También Caínzos y Voces (2014) encuentran que estar en paro aumenta la abstención. En cambio, Pallarés, Fraile y Riba (2007), con datos del CIS, no encuentran relación de la abstención con el nivel educativo ni los ingresos y muy baja relación con la clase social.

Estos análisis están hechos a partir de encuestas, fundamentalmente a partir de encuestas del CIS o de la Encuesta Social Europea. Este procedimiento lo critican Alhambra y Ruiz (2017) pues aducen que las encuestas tienen cierto sesgo que puede invisibilizar a parte de los abstencionistas, y por ello quizás no son el mejor medio para analizar este fenómeno. Ellos analizan la relación entre abstención, renta y estudios con datos electorales a nivel de barrios en Madrid y Barcelona, encontrando una alta relación entre abstención y renta.

Utilizando datos agregados para secciones o barrios Gómez y Trujillo (2011 y 2016) sí encuentran una gran desigualdad en la participación en elecciones, siendo ésta mucho menor en los barrios con mayor presencia de población 
excluida. En Trujillo y Gómez (2019) se encuentra la relación directa entre el porcentaje de abstención y la renta disponible de los barrios de las ciudades.

En los últimos años, a raíz de la difusión de datos de renta primero por barrio y después por sección son muchas las publicaciones que dan cuenta de la relación entre renta y participación (Camarillo y Sánchez 2018, Sánchez 2019, Llaneras y Carretero 2019, Garzón 2019).

La diferencia entre la escasa relación encontrada en las encuestas y la fuerte relación que se encuentra en los análisis de datos de sección o barrio puede ser debido a muchas causas.

Además de las que apuntan Alhambra y Ruiz, hay otras que hay que tener en cuenta: en primer lugar, los análisis con datos agregados se hacen solo con datos urbanos, y funcionan especialmente bien, como se verá más adelante, si se comparan barrios de una misma ciudad, o se relativiza la abstención y los ingresos con respecto a la media de la ciudad. Si se intenta analizar la relación entre abstención e ingresos en el conjunto de las secciones esta relación es muy baja. Ello sugiere que hay un factor de localización en el nivel de abstención que no depende de los ingresos, y que no puede ser tenido en cuenta de forma adecuada en el análisis con encuestas.

Por otra parte, las variables de clase o nivel de estudios brutos no son las mejores para medir la relación, y de hecho la relación es mucho más baja con esas variables que con las de ingresos, variable que no tiene una buena fiabilidad en las encuestas utilizadas en que se pregunta el voto.

\section{LA PARTICIPACIÓN POLÍTICA DE LA POBLACIÓN GITANA}

Hay un factor que brilla por su ausencia tras revisar la literatura clásica de la participación política en España: apenas hay referencias a la participación de gitanos y gitanas. Ni desde el punto de vista de la participación electoral, ni refiriéndose a otras formas de participación.

Por ejemplo, en publicaciones clásicas sobre participación política, como la Navarro (1999) o Castell (1986), no se mencionan en ningún momento, ni para bien ni para mal, la participación de la población gitana. En la monografía de Iglesias et al. (2011) se estudia la evolución de diversas ciudades de España y la acción vecinal, existiendo además un capítulo relacionando la participación política con la exclusión social a través de estudios específicos en barrios de estas 
ciudades, algunos de ellos con una alta proporción de población gitana. Sin embargo, no es mencionado este hecho en todo el libro.

En los estudios realizados mediante encuestas, puede encontrarse la explicación en la ausencia de datos, ya que las fuentes más utilizadas, las encuestas del CIS, no incorporan esta pregunta. Pero en otro tipo de análisis más cualitativos sí sería posible mencionar el papel de los gitanos en los movimientos políticos, aunque fuera para señalar su falta de participación política.

Revisando la literatura específica sobre asociacionismo gitano se confirma la poca participación de gitanos en asociaciones. El asociacionismo específicamente gitano nace en los años 60 vinculado a la iglesia, pero por mucho tiempo esas asociaciones no han sido representativas de los gitanos, sino un consejo al que la Administraciones consultan, cumpliendo una función mediadora entre las instituciones y los gitanos/as, sin crear una conciencia política (San Román, 1997). En general, se argumenta que los gitanos son reacios al asociacionismo, por ser un tipo de estructura que no se corresponde con su tradición, y también por motivos culturales (Méndez 2005).

Poco hay escrito sobre la participación de la comunidad gitana en procesos electorales. En Barany (2015) se menciona que en diversos países del este esta participación ronda el 15\%. En España no hay más cifras que las que ofrecen las encuestas FOESSA (Hernández-Pedreño, Gehring y García-Luque 2019; Damonti y Arza Porras 2014).

Efectivamente, la pertenencia a la población gitana no aparece en las encuestas oficiales, ni tampoco en las del CIS o en la Encuesta Social Europea. Por tanto, la única fuente disponible de datos de encuesta para medir este fenómeno son las encuestas realizadas por la Fundación FOESSA para sus informes sobre exclusión y desarrollo social. Estas encuestas se han publicado en el VI Informe (2008), con datos de 2007, VII Informe (2014, con datos de 2013) y VIII Informe (2019, con datos de 2018). Además, se realizó una intermedia para analizar el primer impacto de la crisis en el año 2009. Su tamaño muestral ha ido aumentando con el tiempo, 3500 en 2007 y 2009, 8769 en 2013 y 11495 en 2018. La forma de identificar a la población gitana es mediante la identificación realizada por el encuestador. No se le pregunta al entrevistado, salvo en la última edición, en la que además de la identificación por el encuestador también se pregunta al entrevistado. En las tablas que se muestran a continuación, para mantener la comparabilidad, se ha utilizado la identificación del encuestador. 
Así, podemos ver en la tabla 1 como más del $25 \%$ de las personas gitanas declaran no votar nunca, mientras que en el total de españoles esta cifra es solo un $6,7 \%$. Sin embargo, los datos de 2018, la última encuesta, mejoran en cierta medida los anteriores, ya que como se puede ver en la tabla 2 ese porcentaje llegó a alcanzar el 39\% en 2013. Además, el porcentaje de personas gitanas que dice que siempre vota llega al $47 \%$ en 2018 , una gran subida desde un $10 \%$ que lo decía en 2007.

Tabla 1. Frecuencia declarada de participación electoral de la población gitana y del conjunto de la población española

\begin{tabular}{|l|c|c|}
\hline & Personas gitanas & Total de españoles \\
\hline Nunca porque no me interesa/ no sirve & $25,7 \%$ & $6,7 \%$ \\
\hline En algunas ocasiones & $18,3 \%$ & $9,5 \%$ \\
\hline Casi siempre & $8,9 \%$ & $17,9 \%$ \\
\hline Siempre & $47,1 \%$ & $65,8 \%$ \\
\hline
\end{tabular}

Fuente: Encuesta FOESSA 2018. Tomado de Trujillo y Gómez, 2019

Tabla 2: Evolución de la participación política entre la población gitana

\begin{tabular}{|l|c|c|c|c|}
\hline & 2007 & 2009 & 2013 & 2018 \\
\hline Nunca porque no me interesa / no sirve & $19,9 \%$ & $37,5 \%$ & $39,1 \%$ & $25,7 \%$ \\
\hline En algunas ocasiones & $18,1 \%$ & $29,1 \%$ & $17,4 \%$ & $18,3 \%$ \\
\hline Casi siempre & $51,2 \%$ & $10,9 \%$ & $7,8 \%$ & $8,9 \%$ \\
\hline Siempre & $10,8 \%$ & $22,5 \%$ & $35,7 \%$ & $47,1 \%$ \\
\hline
\end{tabular}

Fuente: Encuestas FOESSA. Tomado de Trujillo y Gómez (2019)

Para ahondar en este hecho, y dadas las limitaciones que ofrecen las encuestas para estudiarlo, vamos a abordar en este artículo el estudio de la participación en elecciones de forma indirecta, a través del mapa de barrios gitanos elaborado por el Secretariado Gitano en el Mapa de Vivienda y Población Gitana de 2015 (FSG y Daleph 2016). 
Las personas de etnia gitana siguen reuniendo una alta tasa de pobreza, exclusión social, desempleo y bajos niveles de estudios (Fundación Secretariado Gitano 2019; FRA, 2016), por lo que su falta de participación puede venir explicada por esa falta de recursos. En este artículo nos centraremos en estudiar si, como se encuentra en otros estudios para otras minorías (Weeks 2014), la mayor abstención de la población gitana es explicable por esa carencia de recursos.

\section{METODOLOGÍA}

\section{EL MAPA DE VIVIENDA Y POBLACIÓN GITANA}

Este trabajo persigue revelar si los barrios con concentración de población gitana (en adelante, BCPG) tienen un nivel de participación menor que el resto de barrios, y posteriormente si ello puede explicarse por su nivel de pobreza. El principal problema para la materialización de este objetivo es la identificación de las secciones electorales a las que pertenecen estos barrios, a fin de poder calcular la participación de esta población en las elecciones

El Mapa de Vivienda y Población Gitana (FSG y Daleph 2016) es el producto de un estudio realizado entre los años 2015 y 2016 por la Fundación Secretariado Gitano y la empresa Daleph, por encargo del Ministerio de Sanidad, Servicios Sociales e Igualdad. Este estudio sigue una metodología semejante a otros realizados en los años 2007 y 1991. Esta metodología se basa fundamentalmente en la cumplimentación de unas fichas por redes de informantes, con información obtenida a través de observación o consulta directa con entidades sociales, redes profesionales, asociaciones gitanas, vecinales, etc.

Este estudio identifica un conjunto de 2717 barrios con presencia de gitanos, pero se limita a identificarlos con un nombre. No contiene ninguna cartografía que muestre la ubicación de estos barrios. Tampoco existe ninguna identificación de las secciones censales que se corresponden con los barrios. Por tanto, se ha tenido que realizar un trabajo ímprobo de identificación de los barrios seleccionados, así como de su ubicación y asociación con las secciones censales.

\section{IDENTIFICACIÓN DE LOS BARRIOS CON CONCENTRACIÓN DE POBLACIÓN GITANA}

Dada la extensión del mapa de vivienda gitana, no se ha intentado la ubicación de todos los barrios, sino solo aquellos que reúnen mayor población gitana. 
Para ubicar los barrios se han empleado dos vías: cuando en el municipio existe una clasificación oficial de barrios, se ha utilizado esta clasificación. Sin embargo, esta vía a veces es insuficiente, ya que en algunas ciudades los barrios oficiales son muy grandes, reúnen dentro unidades espaciales muy diversas, y la población gitana puede estar concentrada solo en parte del barrio definido administrativamente. En esos casos, y también en los casos en que no existe una clasificación oficial de barrios, se ha utilizado una segunda vía consistente en búsquedas por Internet para localizar los barrios. El proceso de identificación y ubicación ha sido exitoso en la mayoría de los casos. Solo en muy pocos casos no se ha logrado localizar el barrio. En esos pocos casos esta localización no era viable porque la referencia del mapa de vivienda no era a un barrio concreto, sino al municipio entero o a una parte muy grande del mismo. Lo que no se puede tomar como totalmente exacto es la identificación con las secciones, ya que, aunque las referencias encontradas nos hayan permitido ubicar el barrio, los límites del mismo son difíciles de concretar en muchos casos. Por tanto, la asignación de las secciones en las que se concentra la población gitana no es totalmente fiable. También se han encontrado algunos barrios que en el proceso de investigación se han encontrado referencias a la existencia de población gitana, pero que no están en el mapa de vivienda, y también se han incluido.

Finalmente se ha conseguido la localización de 210 barrios pertenecientes a 74 municipios de 29 provincias ${ }^{2}$, abarcando 747 secciones. Según la población estimada en el mapa de vivienda gitana en estos barrios habitan 236375 personas gitanas, lo que supone un $46 \%$ de las personas gitanas que se estiman que viven en los barrios incluidos en el mapa.

Los municipios con más población gitana identificada en diferentes barrios son Madrid (22787 personas), Sevilla (17342), Almería (15061) y Sant Adrià de Besòs (13993). Destaca también que la mayoría de los municipios con barrios gitanos identificados están en Andalucía y la costa mediterránea, aparte de Madrid. Son muy pocos los barrios identificados en el norte y noroeste, aunque sí destaca Bilbao. En el mapa 1 podemos ver los municipios donde se han identificado barrios con concentración de población gitana (en adelante BCPG). El tamaño del círculo es proporcional a la población gitana estimada.

\footnotetext{
${ }^{2}$ No se ha incluido el estudio las ciudades autónomas de Ceuta ni Melilla por las especiales características de estas ciudades.
} 
Mapa 1: Municipios en los que se ha identificado barrios con concentración de población gitana

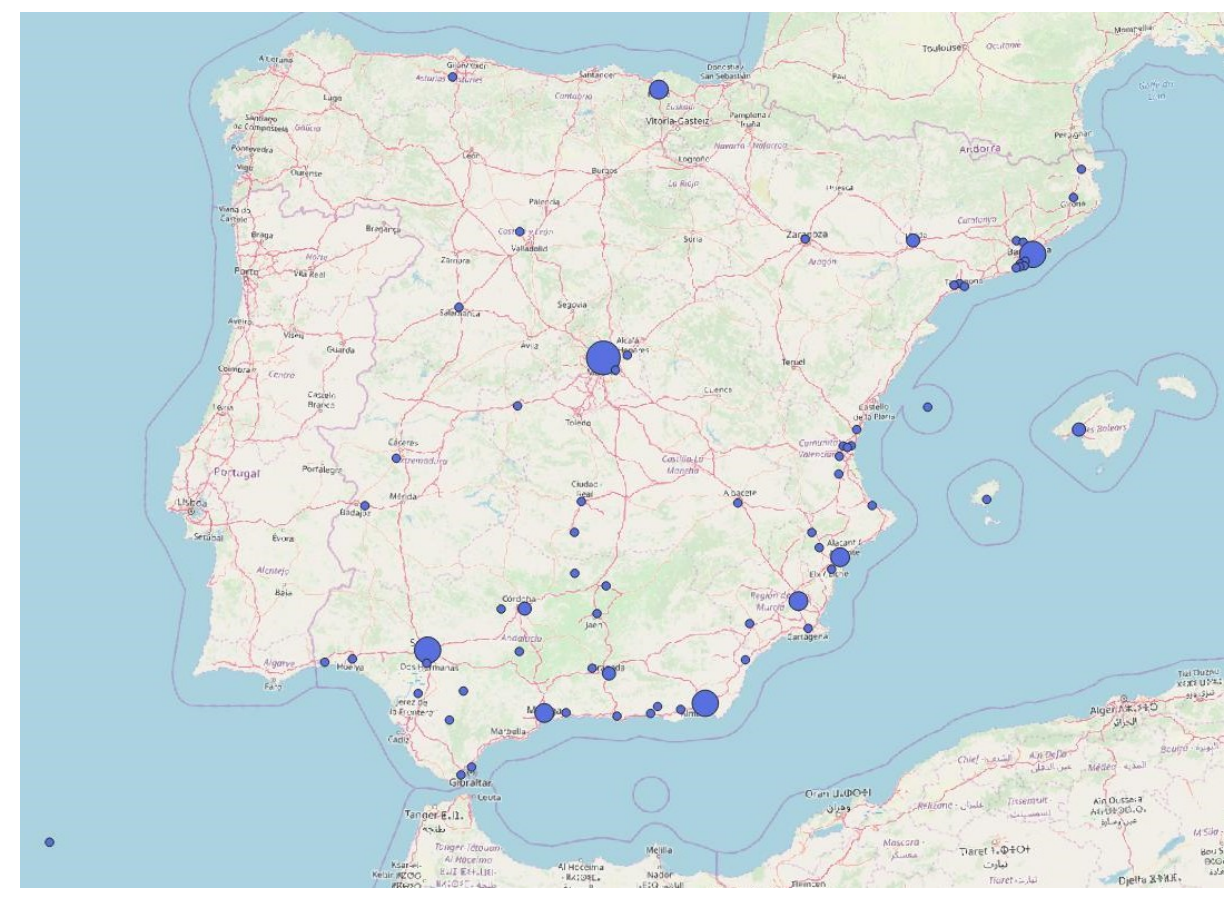

Fuente: elaboración propia a partir del Mapa de Vivienda Gitana (FSG y Daleph, 2016)

\section{CLASIFICACIÓN DE LOS BCPG}

Los informantes del mapa de vivienda gitana (FSG y Daleph 2016) ofrecen una estimación de la población que vive en el barrio. Cotejando esos datos con otros hay que concluir que ese dato tiene una fiabilidad variable, ya que hay ciertos barrios donde la estimación proporcionada por esta fuente está claramente por encima de la realidad, y en otros claramente por debajo. Por ejemplo, hay varios barrios donde la población gitana estimada está por encima de la población censada, lo que es imposible. Por esta circunstancia tomaremos este dato solo como una aproximación, y sin pensar que sea válido en todos los casos.

La población gitana estimada en los barrios que se han identificado, como se ha dicho, es de 236375 personas gitanas. La población total de esos barrios es de 680330 personas, según el Padrón de 2018, por lo que el porcentaje medio estimado de personas gitanas en esos 210 barrios es del 34,7\%. 
Si tratamos de estimar la participación electoral de la población gitana a través de la participación de los barrios en su conjunto, habrá que tener en cuenta la concentración de la población gitana en ese barrio. Para ello, vamos a establecer una clasificación teniendo en cuenta la población gitana estimada, aunque como ya hemos dicho no sea un dato muy exacto.

Tomando como referencia la concentración media, el 34,7\%, clasificaremos como barrios de concentración alta aquellos en que se supere ese valor, que son 90 barrios y los que queden por debajo del 34,7\% los clasificaremos de concentración baja, sumando 120 barrios.

Esta clasificación la tomaremos solo como indicativa a nivel agregado, porque ya se ha dicho que hay muchos factores que hacen que el valor no sea muy riguroso. Además hay que considerar que esa concentración puede no ser uniforme en el barrio. Lo habitual puede ser que en unas secciones haya mayor concentración de población gitana y en otras menos.

$\mathrm{Si}$ nos referimos a secciones, quedan 544 secciones en los 120 barrios de concentración baja y 203 secciones en los 90 barrios de concentración alta (tabla 3)

Tabla 3. Número y porcentaje de secciones según la concentración de población gitana

\begin{tabular}{|l|c|c|}
\hline \multicolumn{1}{|c|}{ Concentración de población gitana } & Número & Porcentaje \\
\hline No gitanos & 10762 & 93,5 \\
\hline Concentración baja & 544 & 4,7 \\
\hline Concentración alta & 203 & 1,8 \\
\hline
\end{tabular}

Fuente: elaboración propia a partir del Mapa de Vivienda Gitana (FSG y Daleph, 2016)

\section{PARTICIPACIÓN EN ELECCIONES POR SECCIÓN}

En este artículo se utilizan los datos de participación en las elecciones generales de 2015, 2016 y abril de 2019, ya que los análisis se hicieron antes de estar disponibles los resultados de las elecciones de noviembre de 2019. Dichos datos están disponibles en la página web del Ministerio del Interior http://www.infoelectoral.mir.es. El dato utilizado es el porcentaje de voto (sea válido o nulo) con respecto al censo electoral. 


\section{RENTA NETA MEDIA DISPONIBLE EN LA SECCIÓN}

En septiembre de 2019 el INE ha publicado por primera vez datos de renta y de pobreza por sección censal. Antes se habían publicado solo datos por distritos para algunas ciudades. La renta, aunque es muy discutida como indicador de bienestar único, es un agregador muy claro de la situación de un hogar, especialmente en hogares con ingresos bajos. Aunque para ser un indicador mejor sería necesario tener en cuenta factores como la disponibilidad o no de vivienda, así como descontar las diferencias de precios según el lugar de residencia, estableciendo diferencias por poder adquisitivo.

Los datos distribuidos por el INE proceden de los datos de renta neta en poder de la Agencia Tributaria agrupados por hogar. Se han publicado datos de renta media y datos de porcentaje de hogares por debajo de ciertos umbrales. El indicador que vamos a utilizar es el porcentaje de hogares en riesgo de pobreza, es decir, por debajo del $60 \%$ de la mediana de sus ingresos por unidad de consumo para el año 2016 (INE 2019). Este indicador es el que correlaciona más fuertemente con la abstención a nivel general. Además, es el utilizado internacionalmente para medir la pobreza ${ }^{3}$.

Los datos publicados por el INE tienen una limitación: están censurados a unos niveles determinados, en el caso de hogares en riesgo de pobreza, todas las secciones con un porcentaje por encima del $63,5 \%$ aparecen con esa cifra.

\section{LA PARTICIPACIÓN ELECTORAL EN LOS BCPG}

\section{RESULTADOS DE ABSTENCIÓN RELATIVA EN ELECCIONES GENERALES}

Los datos de abstención que se han utilizado son los de las elecciones generales de 2015, 2016 y abril de 2019. Se ha preferido estudiar elecciones generales al ser las votaciones que presentan una mayor participación, y donde los resultados son más comparables entre unos lugares y otros. Se ha tomado el promedio de resultados entre las tres elecciones, para utilizar un valor más robusto, ya que en determinadas ocasiones puede haber factores que hagan que baje o suba la participación puntualmente en una elección concreta. En adelante, siempre que se haga referencia a datos de 2019 se referirá a las elecciones de abril de 2019.

\footnotetext{
${ }^{3}$ Ver la definición de población en riesgo de pobreza en el glosario de Eurostat https://ec.europa.eu/eurostat/statistics-explained/index.php?title=Glossary:At-risk-ofpoverty_rate
} 
Para hacer más comparables los resultados que se obtienen entre BCPG y el resto de barrios, el análisis se realiza solo con los 74 municipios en los que se han identificado BCPG. Posteriormente se analiza si las diferencias en abstención encontradas entre estos barrios y el resto se pueden explicar por diferencias de renta. La participación electoral es una variable que está afectada por circunstancias locales, es decir, hay municipios en que, bien sistemática o bien puntualmente, se vota más que en otros. La comparación directa de la abstención de los distintos barrios estudiados se olvidaría de estas particularidades locales y haría aún más difícilmente comparables los datos. Por ello, al igual que en un estudio anterior (Gómez y Trujillo 2011), se va a estudiar principalmente la diferencia entre la abstención de la sección o el barrio y la abstención del municipio. Es decir, al porcentaje de abstención en la sección se le resta el porcentaje de abstención en el conjunto del municipio para obtener la variable diferencia de abstención, que será la que se utilice principalmente. Como se verá, las correlaciones de esta variable con otras también relativizadas con el valor municipal es mucho mayor que las correlaciones de los valores originales.

Si miramos el histograma de esta variable (gráfico 1), vemos que es casi simétrico, salvo por una pequeña pero larga cola de secciones con mucha más abstención que la media de sus municipios.

Gráfico 1. Histograma de la variable diferencia de abstención

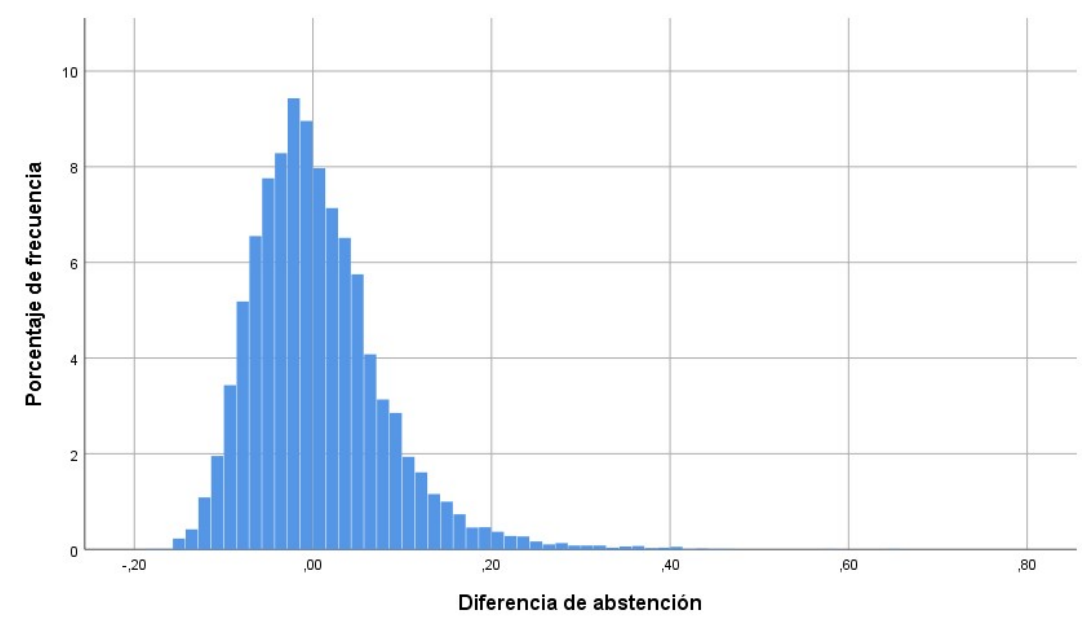

Fuente: Elaboración propia a partir de datos de resultados de elecciones, Ministerio del Interior 
En la tabla 4 podemos ver que solo 57 secciones, el 0,5\% de las que hay, tienen una diferencia de abstención por encima de 30 puntos, y 161, el 1,4\%, una diferencia entre 20 y 30 puntos.

Tabla 4. Número y porcentaje de secciones según su abstención relativa

\begin{tabular}{|l|c|c|}
\hline \multicolumn{1}{|c|}{ Diferencia de abstención } & Número & Porcentaje \\
\hline Por debajo de la media & 6131 & 53,3 \\
\hline Menor de 10\% & 4308 & 37,4 \\
\hline Entre 10\% y 20\% & 850 & 7,4 \\
\hline Entre 20\% y 30\% & 161 & 1,4 \\
\hline Por encima del 30\% & 57 & 0,5 \\
\hline
\end{tabular}

Fuente: Elaboración propia a partir de datos de resultados de elecciones, Ministerio del Interior

\section{EVOLUCIÓN DE LA ABSTENCIÓN RELATIVA EN LOS BCPG}

Como era de esperar, la abstención es más alta en las secciones incluidas en los barrios con concentración de población gitana (BCPG). No solo eso, sino que también varía según la concentración de las secciones (tabla 5), con un promedio del $26 \%$ en barrios no BCPG, un 39\% en barrios de concentración baja, y un $49 \%$ en barrios con concentración alta.

Una de las explicaciones habituales a la falta de participación en la población gitana es la falta de candidatos de esta etnia (de la Flor 1997). En el año 2019 ha habido, después de cuarenta años, candidatos gitanos y se han elegido a cuatro diputados gitanos (Europa Press 2019), ello no parece que haya hecho subir la participación en estos barrios, sino que la diferencia con el resto de barrios incluso aumenta, pasando de 22 puntos en 2015 a 26 puntos en 2019 (Tabla 5). 
Tabla 5. Abstención según la concentración de población gitana

\begin{tabular}{|l|l|c|c|c|c|}
\hline \multicolumn{2}{|c|}{} & 2015 & 2016 & 2019 & Promedio \\
\hline \multirow{2}{*}{$\begin{array}{l}\text { Nivel de } \\
\text { concentración }\end{array}$} & No BCPG & $26 \%$ & $29 \%$ & $23 \%$ & $26 \%$ \\
\cline { 2 - 5 } & BCPG baja & $38 \%$ & $42 \%$ & $36 \%$ & $39 \%$ \\
\cline { 2 - 6 } & BCPG alta & $48 \%$ & $52 \%$ & $48 \%$ & $49 \%$ \\
\hline
\end{tabular}

Fuente: Elaboración propia a partir de datos de resultados de elecciones, Ministerio del Interior y Mapa de Vivienda Gitana

Como ya hemos dicho el fenómeno se analiza mejor si atendemos a la variable de diferencia de abstención, y así eliminamos posibles cambios en la abstención que afecten de forma distinta a determinadas zonas de España. Atendiendo a esta variable la conclusión es (tabla 6) que la diferencia de abstención de los barrios con concentración de población gitana alta prácticamente no varía, y se sitúa en los tres años en los 20 puntos.

Tabla 6. Diferencia de abstención con el promedio municipal según la concentración de población gitana

\begin{tabular}{|l|l|c|c|c|c|}
\hline \multicolumn{2}{|c|}{} & 2015 & 2016 & 2019 & Promedio \\
\hline $\begin{array}{l}\text { Nivel de } \\
\text { concentración }\end{array}$ & No BCPG & 0,00 & 0,00 & $-0,01$ &, 00 \\
\cline { 2 - 6 } & BCPG baja & 0,12 & 0,11 & 0,11 & 0,11 \\
\cline { 2 - 6 } & BCPG alta & 0,21 & 0,20 & 0,20 & 0,20 \\
\hline
\end{tabular}

Fuente: Elaboración propia a partir de datos de resultados de elecciones, Ministerio del Interior y Mapa de Vivienda Gitana

En el gráfico 2 podemos ver qué porcentaje de BCPG hay según el diferencial de abstención. Se advierte que entre las secciones con menos abstención que la media apenas hay secciones en barrios gitanos. Muy pocos hay en las secciones con una diferencia de menos de 10 puntos. Más hay en las secciones con un porcentaje entre el $10 \%$ y el $20 \%$ : cerca de un $20 \%$. Pero casi todas estas secciones corresponden a barios con concentración baja de gitanos. En las secciones con una diferencia entre el $20 \%$ y el $30 \%$ ya son mayoría las secciones de BCPG, aunque aún son mayoría los barrios con concentración baja, ya hay un 
$30 \%$ de barrios con presencia alta. Finalmente, las secciones con más de 30\% de diferencia casi todas corresponden a BCPG, y casi un $70 \%$ a barrios con concentración alta.

Gráfico 2: Porcentaje de secciones según intervalos de diferencias de abstención con respecto a la media municipal

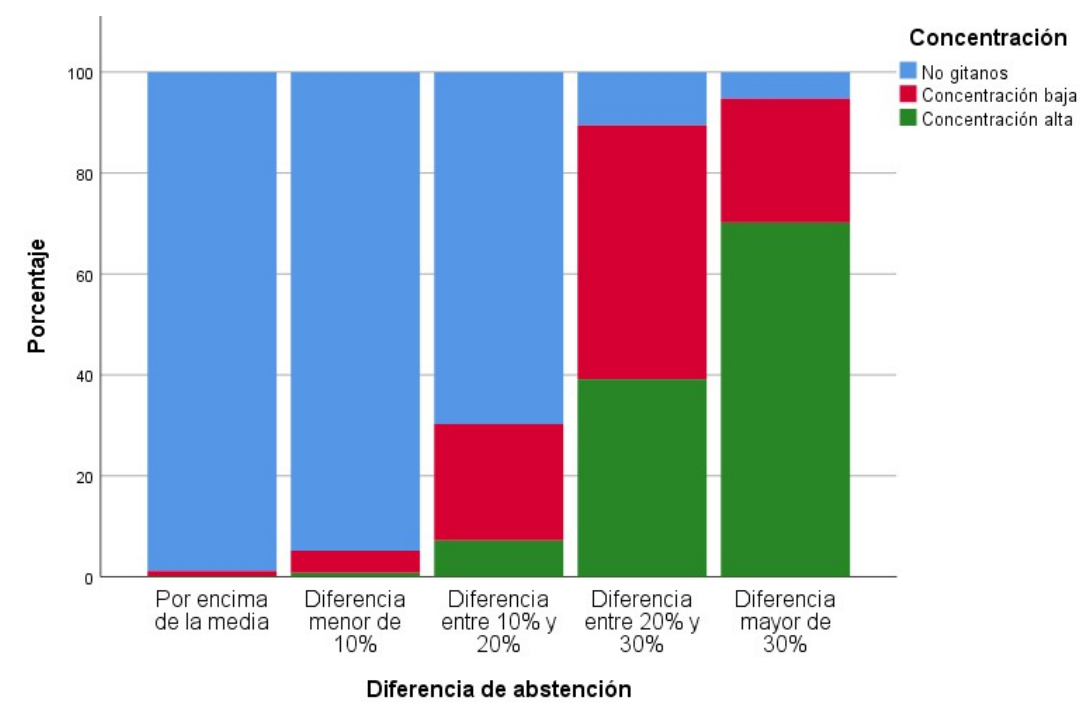

Fuente: Elaboración propia a partir de datos de resultados de elecciones, Ministerio del Interior y Mapa de Vivienda Gitana

En la tabla 7 podemos ver el número de secciones según su concentración y la diferencia de abstención con la media municipal. Vemos que hay muy pocas secciones en BCPG en donde la abstención esté por debajo de la media, siendo solo 6 las secciones en BCPG con concentración alta donde la abstención está por debajo de la media.

Las tres secciones con más de $30 \%$ de diferencia de abstención que no se corresponden con BCPG son secciones de Madrid, dos en Madrid capital y una en Ciempozuelos, donde hay grandes residencias de ancianos, que tienen un bajo porcentaje de participación. 
Tabla 7: Número de secciones según concentración de población gitana y diferencia de abstención con la media municipal

\begin{tabular}{|c|c|c|c|c|c|c|}
\hline & \multicolumn{5}{|c|}{ Diferencia de abstención } \\
\hline & & $\begin{array}{l}\text { Menor de } 0 \\
\text { (abstención } \\
\text { debajo de la } \\
\text { media) }\end{array}$ & $\begin{array}{c}\text { Menor } \\
\text { de } \\
10 \%\end{array}$ & $\begin{array}{c}10 \% \\
\mathrm{a} \\
20 \%\end{array}$ & $\begin{array}{c}20 \% \\
\text { a } \\
30 \%\end{array}$ & $\begin{array}{c}\text { Más } \\
\text { de } \\
30 \%\end{array}$ \\
\hline \multirow[t]{3}{*}{ Concentración } & No BCPG & 6081 & 4068 & 593 & 17 & 3 \\
\hline & BCPG baja & 64 & 189 & 196 & 81 & 14 \\
\hline & BCPG alta & 6 & 33 & 61 & 63 & 40 \\
\hline
\end{tabular}

Fuente: Elaboración propia a partir de datos de resultados de elecciones, Ministerio del Interior y Mapa de Vivienda Gitana

\section{RELACIÓN ENTRE PARTICIPACIÓN POLÍTICA Y POBREZA}

\section{FUENTES DE DATOS}

En los artículos de Gómez y Trujillo (2016; 2011) se prueba que la exclusión social, y en general las desventajas sociales, están relacionadas con la abstención electoral. Los barrios donde la mayoría de la población experimenta situaciones de pobreza son también los que más abstención electoral presentan. Hay que preguntarse entonces si la mayor abstención en los barrios con mayor concentración de población gitana no es causada realmente por las situaciones de pobreza que marcan la situación de estos barrios. Como se ha explicado en el apartado de metodología, se utilizarán los datos del INE sobre porcentaje de hogares pobres en cada sección, que a su vez proceden de la Agencia Tributaria.

$\mathrm{Al}$ igual que en los casos anteriores, para estandarizar la situación de una sección con respecto a su entorno, se calculará la diferencia con respecto al porcentaje en el municipio en su conjunto.

El histograma de esta variable es bastante similar al de la abstención, aunque la cola a la derecha es menor en este caso. Es decir, hay menos secciones con una alta diferencia de porcentaje de pobreza que con una alta diferencia de abstención. 
Gráfico 4: Histograma de la variable diferencia de \% de hogares en riesgo de pobreza con respecto a la media municipal

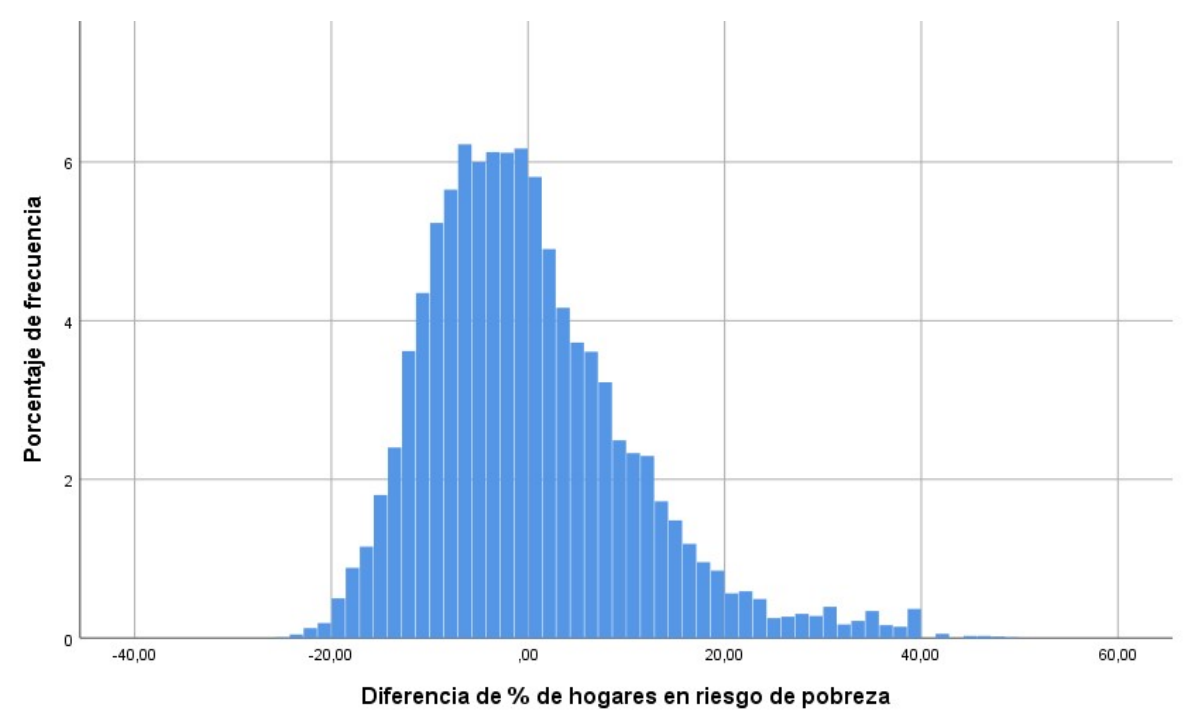

Fuente: Atlas de distribución de la renta de los hogares (INE, 2019)

\section{RELACIÓN ENTRE POBREZA Y ABSTENCIÓN}

Como se mencionó al principio, la relación entre abstención y pobreza no se advierte apenas si se analizan los datos globalmente. La correlación entre porcentaje de abstención y porcentaje de hogares pobres en los municipios seleccionados es solo del 22,7\%. Esto casa con la poca relación que se encuentra en los estudios realizados a partir de encuestas. En cambio, si se relativizan los datos restando la media municipal de ambos indicadores la correlación se dispara por encima del $90 \%$ (Tabla 8 ).

Tabla 8. Correlaciones entre abstención y porcentaje de hogares en riesgo de pobreza.

\begin{tabular}{|l|c|}
\hline & Correlación \\
\hline Valores brutos & 0,227 \\
\hline Diferencia con los valores medios municipales & 0,902 \\
\hline
\end{tabular}

Fuente: Atlas de distribución de la renta de los hogares (INE, 2019) y resultados de elecciones (Ministerio del Interior) 


\section{LA POBREZA EN LOS BCPG}

Si se toma el porcentaje de hogares en riesgo de pobreza como indicador esta cifra apenas tiene diferencia entre los BCPG con respecto a los demás (tabla 9). Es decir, la diferencia de ingresos, y por tanto de pobreza entre los municipios es tanta, que prevalece sobre las diferencias internas en los municipios. En cambio, si tomamos la variable diferencia de porcentaje de pobreza con respecto al municipio, y por tanto anulamos la diferencia de nivel de pobreza con respecto a los municipios, sí que aparece una enorme distancia entre el valor de $-1,30 \%$ en los barrios sin concentración de población gitana, hasta el valor del $25 \%$ de los BCPG con concentración alta. Es decir, los barrios con concentración alta de población gitana tienen un $25 \%$ más de personas pobres que la media de sus municipios.

Tabla 9. Porcentaje de hogares en riesgo de pobreza según la concentración de personas gitanas

\begin{tabular}{|l|l|c|c|}
\hline \multicolumn{2}{|c|}{} & $\begin{array}{c}\text { \% de hogares } \\
\text { en riesgo de } \\
\text { pobreza }\end{array}$ & $\begin{array}{c}\text { Diferencia media de \% } \\
\text { de hogares en riesgo de } \\
\text { pobreza }\end{array}$ \\
\hline \multirow{2}{*}{$\begin{array}{l}\text { Nivel de } \\
\text { concentración }\end{array}$} & No gitano & $21,3 \%$ & $-1,30$ \\
\cline { 2 - 4 } & Baja & $23,0 \%$ & 16,36 \\
\cline { 2 - 4 } & Alta & $25,5 \%$ & 25,40 \\
\hline
\end{tabular}

Fuente: Elaboración propia a partir del Atlas de distribución de la renta de los hogares (INE, 2019) y Mapa de Vivienda Gitana

\section{ANÁLISIS DE LA ABSTENCIÓN EN BARRIOS GITANOS TENIENDO EN CUENTA SU NIVEL DE POBREZA}

En este epígrafe vamos analizar si la diferencia de participación en los barrios con presencia gitana puede deberse a su situación económica, que como hemos visto está fuertemente relacionada con la abstención. Anteriormente hemos visto que, si en los BCPG hay mayor abstención, también hay mayor riesgo de pobreza. Para analizar si ese factor puede explicar las diferencias de abstención entre BCPG y el resto, realizamos un análisis lineal, donde tomamos como variable dependiente la diferencia de abstención, independientes la diferencia en riesgo de pobreza, y la concentración de personas gitanas como factor fijo. El resultado, en la Tabla 10, es que el riesgo de pobreza tiene una gran influencia en la abstención. 
Tabla 10: Modelo lineal de ajuste

\begin{tabular}{|l|r|r|r|r|}
\hline \multicolumn{5}{|c|}{ Variable dependiente: } \\
\hline & \multicolumn{1}{|c|}{ Diferencia de abstención } \\
\hline Parámetro & $\mathrm{B}$ & \multicolumn{1}{c|}{$\begin{array}{c}\text { Desv. } \\
\text { Error }\end{array}$} & \multicolumn{1}{c|}{$\mathrm{t}$} & $\begin{array}{c}\text { Eta parcial al } \\
\text { cuadrado }\end{array}$ \\
\hline Intersección &, 052 &, 002 & 21,533 &, 040 \\
\hline Dif. De riesgo de pobreza &, 006 & $3,198 \mathrm{E}-5$ & 189,477 &, 763 \\
\hline NO BCPG &,- 048 &, 002 & $-19,864$ &, 034 \\
\hline Concentración baja &,- 035 &, 003 & $-13,127$ &, 015 \\
\hline Concentración alta & 0 & & &. \\
\hline
\end{tabular}

a. Este parámetro está establecido en cero porque es redundante. Fuente: Elaboración propia

Gráfico 5. Medias marginales estimadas de diferencia de abstención para el modelo lineal

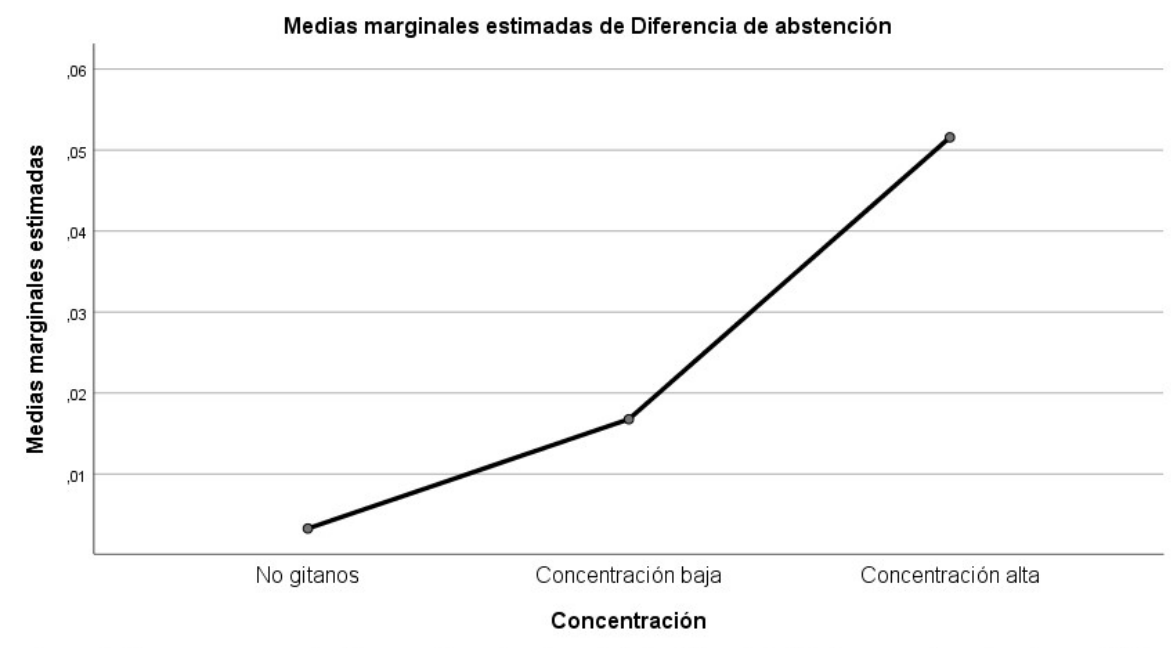

Las covariables que aparecen en el modelo se evalúan en los valores siguientes: Diferencia de \% de hogares en riesgo de pobreza = -,0099

Fuente: Elaboración propia 
En el gráfico 5 podemos ver las medias marginales estimadas de la variable de diferencia de abstención. Estos valores son los que se obtienen al eliminar la parte de la variable explicada por el resto del modelo. Si con los valores directos de diferencia de abstención ésta era de 0,20 para las concentraciones altas y 0,11 para las bajas, al incluir estas variables esa diferencia se reduce muchísimo, quedando en 0,06 para las concentraciones altas, y 0,018 para las concentraciones bajas. Sigue habiendo diferencia, pero es mucho más pequeña.

Otra forma de demostrar la escasa diferencia de abstención entre los tipos de barrios cuando se controla por el porcentaje de pobreza es mediante el gráfico de dispersión de abstención (Gráfico 6) frente a riesgo de pobreza, donde se ha realizado un ajuste local para cada grupo de presencia gitana. Se ve como las líneas de ajuste, todas crecientes, tienen una separación mínima.

Gráfico 6. Gráfico de dispersión de la diferencia de abstención frente diferencia de $\%$ de hogares en riesgo de pobreza con ajuste local según la presencia gitana

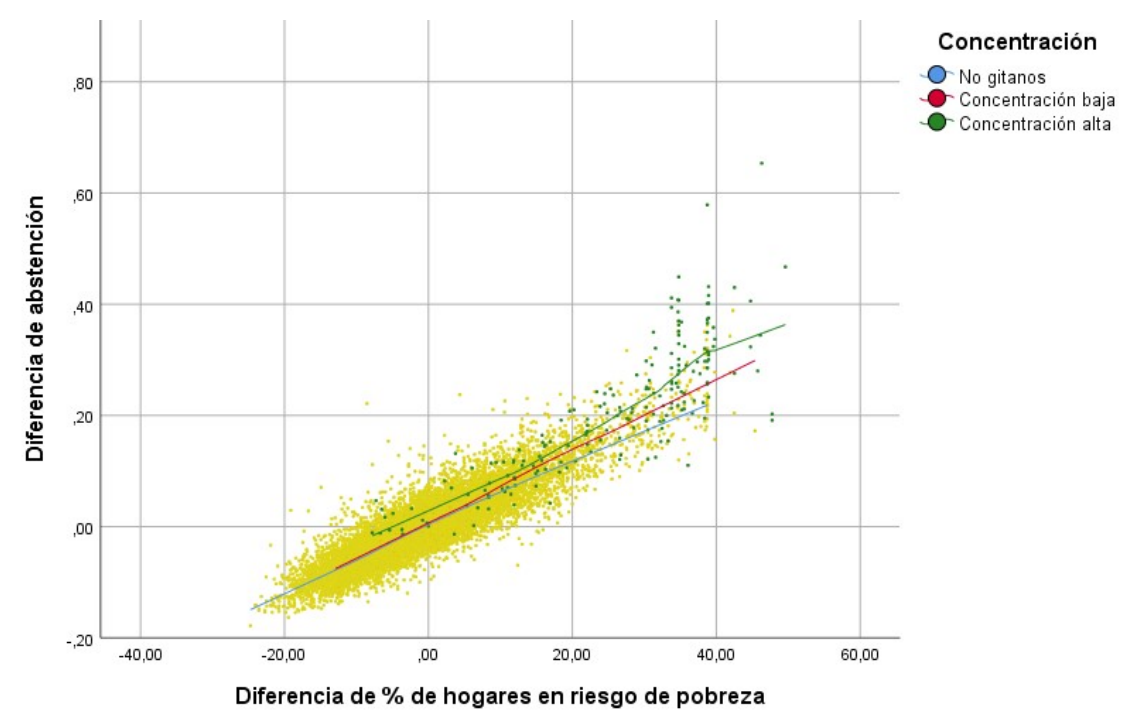

Fuente: Elaboración propia 
Podemos concluir, por tanto, que casi todo el efecto de que la abstención sea mayor en los barrios con concentración de población gitana se puede explicar por su baja renta. La parte que no se puede explicar podría atribuirse a la especificidad de la población gitana, pero también podría ser igualmente debida a otros factores sociales que no se han medido.

\section{ANÁLISIS DE LA ABSTENCIÓN Y LA POBREZA EN LOS BARRIOS DE TRES CIUDADES}

Vamos a describir con los barrios concretos la situación en tres ciudades. Hemos elegido Madrid y Sevilla, por ser dos de las ciudades donde más población gitana hay y donde mayor es la diferencia entre barrios tanto en porcentaje de abstención como en porcentaje de población pobre. Y hemos elegido Huelva para estudiar si ha tenido algún efecto la presencia de un candidato gitano en el voto en los barrios de esta ciudad.

\section{MADRID}

En el caso de Madrid ha sido particularmente difícil identificar los barrios, ya que en el mapa de vivienda gitana venían identificados de forma muy genérica, la mayoría como realojos de la Empresa Municipal de Vivienda y Suelo de Madrid (EMVS) de los distintos distritos. Por ello se ha tenido que buscar la localización de las promociones de la EMVS (EMVS, 2017), gracias a la web www.datanalytics.com. En este caso, al ser las estimaciones de población gitana referidas a todo el distrito, todas salen como concentración baja, aunque sin duda habrá zonas con concentración alta. La única excepción son algunos barrios que sí son identificados independientemente como Cañada Real.

Como se ha dicho anteriormente los datos que ofrece el INE están censurados tanto por arriba como por debajo. De forma que el porcentaje de pobreza mínima que muestra es el $2,4 \%$ y el máximo el $63,5 \%$, aunque puede haber secciones donde en realidad haya porcentajes de pobreza inferiores al mínimo o superiores al máximo. Por ello el porcentaje de pobreza que se recoge en Madrid va desde el 2,4\%, hasta el 63,5\% de Cañada Real (distrito Vallecas), es decir, que tenemos desde la sección con más pobres a la sección con menos pobres. El porcentaje de abstención en promedio va desde 9,6\% en una sección de El Goloso hasta el 89\% de la mencionada Cañada Real. 
Como se ve en el gráfico 7 la relación es muy clara, con una correlación del $92,4 \%$

Gráfico 7. Gráfico de dispersión de secciones de Madrid por porcentaje de hogares en riesgo de pobreza y abstención promedio 2015-2019

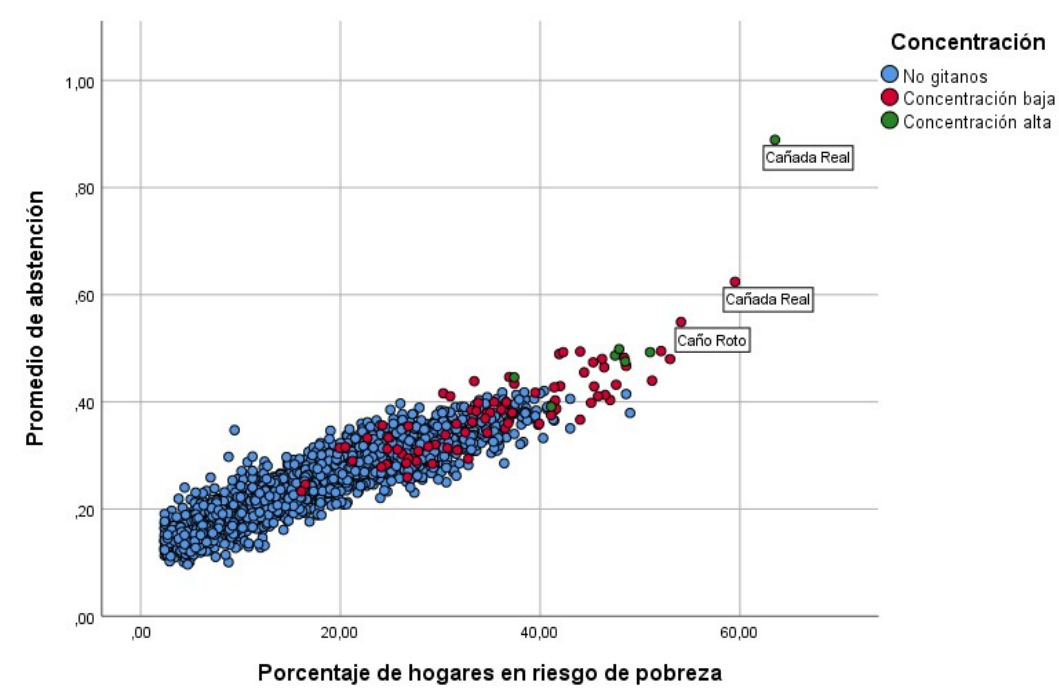

Fuente: Resultados de elecciones, Ministerio del Interior y Atlas de distribución de la renta de los hogares (INE, 2019)

En la tabla 13 aparecen los valores de abstención de los barrios identificados, tanto el promedio del barrio como el valor de la sección con mayor abstención. También se indica el porcentaje de hogares en riesgo de pobreza, tanto el promedio como la abstención con más porcentaje. Más abajo se indican los valores para el resto de barrios, dividido por distritos

Vemos que los valores de abstención en los BCPG son muy superiores, pero también los porcentajes de pobreza. En algunos barrios, como se ve, hay secciones con porcentajes mucho más altos en alguna sección, como Entrevías Oeste o Triángulo del Agua, lo que indica que la distribución de la población no es homogénea en todo el barrio, con lo que probablemente tampoco lo sea la distribución de la población gitana. 
Tabla 13: Abstención y Porcentaje de hogares en riesgo de pobreza por distritos y BCPG en Madrid

\begin{tabular}{|c|c|c|c|c|c|}
\hline & & \multicolumn{2}{|c|}{ \% de abstención } & \multicolumn{2}{|c|}{ \% en riesgo de pobreza } \\
\hline Barrio* & Distrito & Media & Máxim & Media & Máximo \\
\hline Cañada Real & Villa de Vallecas & $88,9 \%$ & $88,9 \%$ & $63,5 \%$ & $63,5 \%$ \\
\hline Cañada Real & Vicálvaro & $62,4 \%$ & $62,4 \%$ & $59,5 \%$ & $59,5 \%$ \\
\hline Caño Roto & La Latina & $51,6 \%$ & $54,9 \%$ & $51,3 \%$ & $54,1 \%$ \\
\hline El Ruedo & Moratalaz & $49,5 \%$ & $49,5 \%$ & $52,1 \%$ & $52,1 \%$ \\
\hline Plata y Castañar & Villaverde & $49,3 \%$ & $49,3 \%$ & $42,3 \%$ & $42,3 \%$ \\
\hline Alto de San Isidro & Carabanchel & $48,4 \%$ & $49,3 \%$ & $49,8 \%$ & $51,0 \%$ \\
\hline Las Torres & Villaverde & $48,0 \%$ & $48,0 \%$ & $53,0 \%$ & $53,0 \%$ \\
\hline Pan Bendito & Carabanchel & $45,5 \%$ & $49,8 \%$ & $42,8 \%$ & $47,9 \%$ \\
\hline Quinta del Pilar & Villaverde & $45,5 \%$ & $45,5 \%$ & $44,4 \%$ & $44,4 \%$ \\
\hline San Cristobal & Villaverde & $43,2 \%$ & $49,4 \%$ & $44,4 \%$ & $51,2 \%$ \\
\hline Amposta & San Blas & $42,3 \%$ & $43,9 \%$ & $34,3 \%$ & $39,5 \%$ \\
\hline Eje Marcelo Usera & Usera & $38,9 \%$ & $42,7 \%$ & $40,4 \%$ & $49,0 \%$ \\
\hline Orcasur & Usera & $38,7 \%$ & $48,9 \%$ & $33,7 \%$ & $42,0 \%$ \\
\hline Colonia Los Olivos & La Latina & $38,7 \%$ & $38,7 \%$ & $41,6 \%$ & $41,6 \%$ \\
\hline Almendrales & Usera & $37,9 \%$ & $42,9 \%$ & $39,3 \%$ & $45,4 \%$ \\
\hline La Cornisa & Usera & $37,7 \%$ & $39,8 \%$ & $29,0 \%$ & $33,8 \%$ \\
\hline La Perla & Usera & $36,7 \%$ & $36,7 \%$ & $44,0 \%$ & $44,0 \%$ \\
\hline Triángulo del Agua & Puente De Vallecas & $35,7 \%$ & $47,4 \%$ & $32,8 \%$ & $45,3 \%$ \\
\hline $\begin{array}{ll}\text { Colonia } & \text { Antonio } \\
\text { Blasco } & \\
\end{array}$ & Latina & $34,8 \%$ & $38,0 \%$ & $30,5 \%$ & $34,7 \%$ \\
\hline $\begin{array}{ll}\text { Pozo del Tío } \\
\text { Raimundo }\end{array}$ & Puente De Vallecas & $33,9 \%$ & $38,0 \%$ & $33,5 \%$ & $37,2 \%$ \\
\hline UVA Hortaleza & Hortaleza & $33,6 \%$ & $38,3 \%$ & $24,2 \%$ & $33,6 \%$ \\
\hline Entrevías Oeste & Puente De Vallecas & $33,2 \%$ & $46,5 \%$ & $31,6 \%$ & $47,0 \%$ \\
\hline $\begin{array}{lll}\text { Camino } & \text { de } & \text { la } \\
\text { Vereda } & & \\
\end{array}$ & Villa De Vallecas & $31,7 \%$ & $31,7 \%$ & $28,8 \%$ & $28,8 \%$ \\
\hline
\end{tabular}




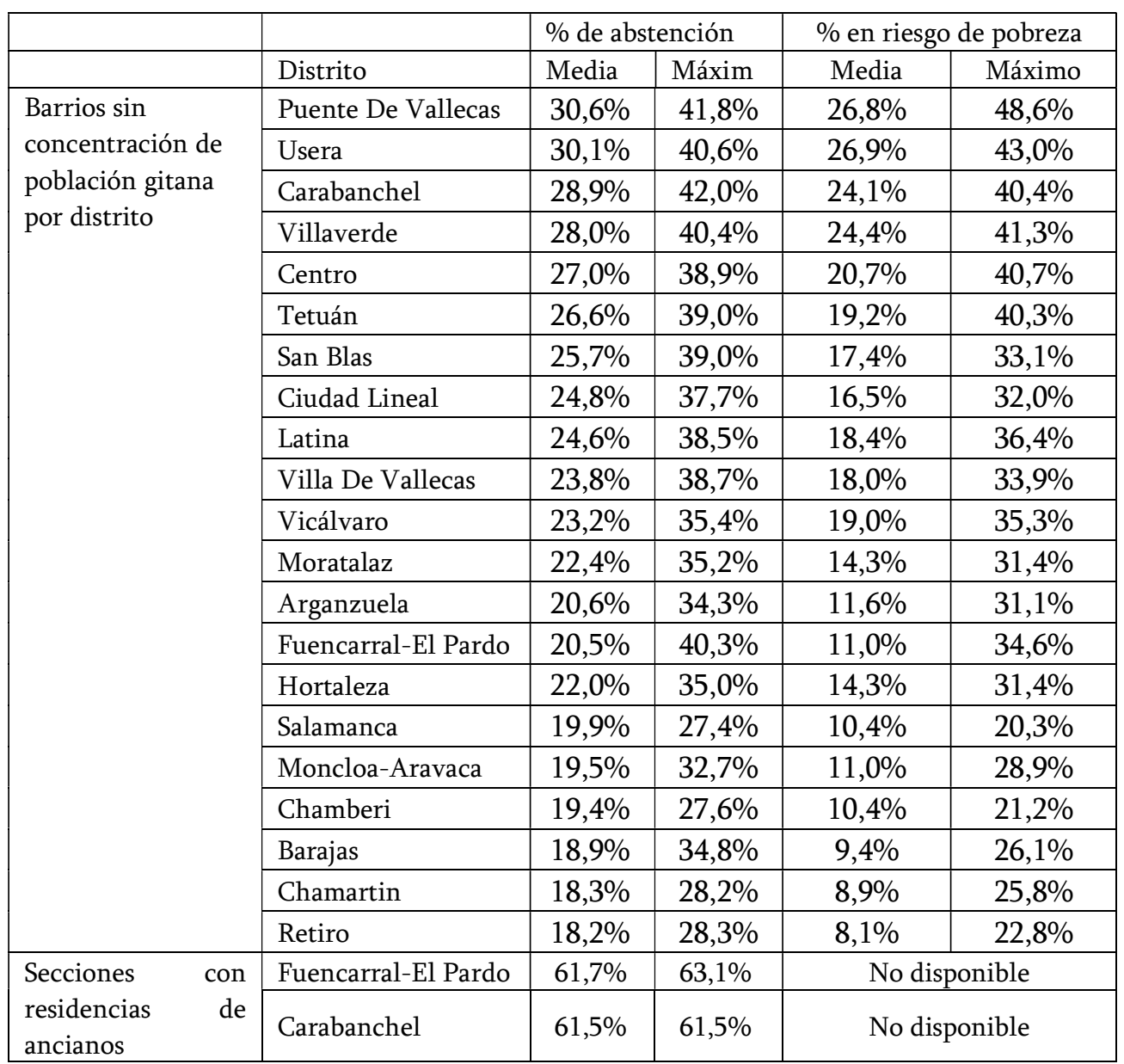

${ }^{*}$ según diversas denominaciones

Fuente: Resultados de elecciones, Ministerio del Interior y Atlas de distribución de la renta de los hogares (INE, 2019)

\section{SEVILLA}

En Sevilla los BCPG aparecen en el mapa de vivienda gitana con bastante detalle, por lo que no resulta complicado localizarlos, salvo algún caso. Las zonas de Torreblanca y Polígono Sur, divididas en varios barrios en el mapa de vivienda gitana, reúnen los mayores porcentajes de abstención y también de riesgo de pobreza, aunque en muchos casos el valor que da el INE es el máximo que ofrece, $63,5 \%$, suponiendo que en realidad será mayor ese porcentaje (gráfico 8). La correlación 
En este caso se ve también que hay secciones con alta abstención y pobreza en barrios que, en principio, no se han identificado como gitanos (los que aparecen con el punto azul). Las que más tasa de pobreza tienen sin estar en barrios incluidos en el mapa de vivienda gitana son dos secciones en los barrios La Plata y El Cerezo, con un 63,2\% y un 62,6\% respectivamente. También una sección del Polígono Norte, con un $63 \%$ de pobreza y un alto porcentaje de abstención del $48 \%$.

Gráfico 8: Gráfico de dispersión de secciones de Sevilla por porcentaje de hogares en riesgo de pobreza y abstención promedio 2015-2019

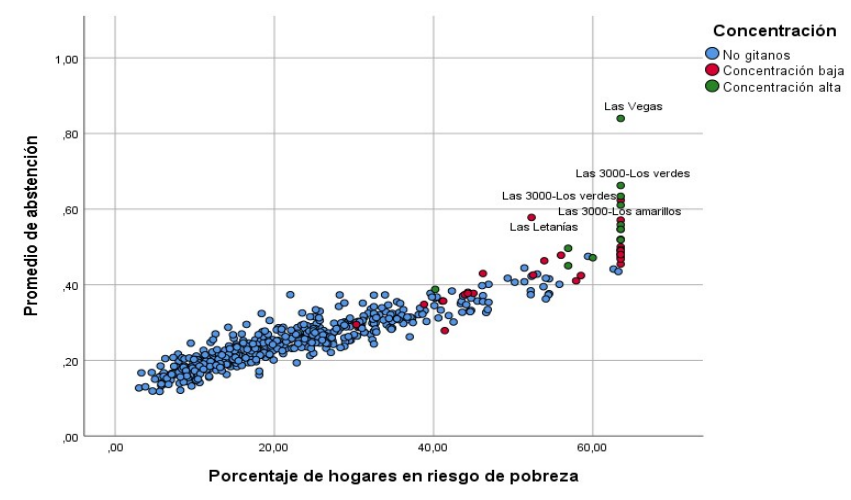

Fuente: Resultados de elecciones, Ministerio del Interior y Atlas de distribución de la renta de los hogares (INE, 2019)

En la tabla 14 aparecen los valores de abstención de los barrios identificados, tanto el promedio del barrio como el valor de la sección con mayor abstención. También se indica el porcentaje de hogares en riesgo de pobreza, tanto el promedio como la abstención con más porcentaje. Más abajo se indican los valores para el resto de barrios, dividido por distritos

Vemos que los valores de abstención en los BCPG son muy superiores al conjunto de los barrios de Sevilla, y más aún los porcentajes de pobreza. Las zonas de Las 3000 viviendas, en el Distrito Sur, y Torreblanca destacan ampliamente por su porcentaje de abstención y pobreza. 
Tabla 14: Abstención y Porcentaje de hogares en riesgo de pobreza por distritos y barrios gitanos en Sevilla

\begin{tabular}{|c|c|c|c|c|c|}
\hline & & \multicolumn{2}{|c|}{ \% de abstención } & \multicolumn{2}{|c|}{$\%$ en riesgo de pobreza } \\
\hline Barrio* & Distrito & Media & Máximo & Media & Máximo \\
\hline Las Vegas & Sur & $66,8 \%$ & $84,0 \%$ & $60,2 \%$ & $63,5 \%$ \\
\hline Las 3000-Los verdes & Sur & $64,8 \%$ & $66,3 \%$ & $63,5 \%$ & $63,5 \%$ \\
\hline Torreblanca-Casitas bajas & Este-Alcosa-Torreblanca & $61,1 \%$ & $61,1 \%$ & $63,5 \%$ & $63,5 \%$ \\
\hline Las 800 & Sur & $55,9 \%$ & $55,9 \%$ & $63,5 \%$ & $63,5 \%$ \\
\hline Las 3000-Los rojos & Sur & $54,7 \%$ & $54,7 \%$ & $63,5 \%$ & $63,5 \%$ \\
\hline Torreblanca-blancos & Este-Alcosa-Torreblanca & $53,3 \%$ & $54,7 \%$ & $63,5 \%$ & $63,5 \%$ \\
\hline Las Letanías & Sur & $51,0 \%$ & $57,8 \%$ & $56,6 \%$ & $63,5 \%$ \\
\hline Las 3000-Los marrones & Sur & $49,6 \%$ & $52,0 \%$ & $61,8 \%$ & $63,5 \%$ \\
\hline Las 3000-Los amarillos & Sur & $49,0 \%$ & $62,4 \%$ & $52,4 \%$ & $63,5 \%$ \\
\hline $\begin{array}{ll}\text { Torreblanca-Las } & \text { Tres } \\
\text { Calles y Modecar } & \\
\end{array}$ & Este-Alcosa-Torreblanca & $48,0 \%$ & $48,0 \%$ & $63,5 \%$ & $63,5 \%$ \\
\hline Los Pajaritos & Cerro - Amate & $45,9 \%$ & $57,1 \%$ & $58,7 \%$ & $63,5 \%$ \\
\hline Los Carteros & Macarena Norte & $43,0 \%$ & $43,0 \%$ & $46,2 \%$ & $46,2 \%$ \\
\hline Antonio Machado & Sur & $41,9 \%$ & $45,0 \%$ & $48,6 \%$ & $56,9 \%$ \\
\hline $\begin{array}{l}\text { Paz y Amistad-Los } \\
\text { Merrys }\end{array}$ & Sur & $37,7 \%$ & $37,7 \%$ & $44,3 \%$ & $44,3 \%$ \\
\hline El Vacie & Macarena & $34,8 \%$ & $34,8 \%$ & $38,8 \%$ & $38,8 \%$ \\
\hline $\begin{array}{l}\text { Paz y Amistad-Casitas } \\
\text { bajas }\end{array}$ & Sur & $29,5 \%$ & $29,5 \%$ & $30,3 \%$ & $30,3 \%$ \\
\hline $\begin{array}{l}\text { Torreblanca-Las } \\
\text { Lumbreras }\end{array}$ & Este-Alcosa-Torreblanca & $27,9 \%$ & $27,9 \%$ & $41,4 \%$ & $41,4 \%$ \\
\hline \multirow{11}{*}{$\begin{array}{l}\text { Barrios sin presencia } \\
\text { gitana }\end{array}$} & Cerro - Amate & $31,6 \%$ & $43,5 \%$ & $35,1 \%$ & $63,2 \%$ \\
\hline & Macarena & $29,9 \%$ & $47,9 \%$ & $30,0 \%$ & $63,5 \%$ \\
\hline & San Pablo - Santa Justa & $26,5 \%$ & $39,7 \%$ & $23,2 \%$ & $46,2 \%$ \\
\hline & Macarena Norte & $26,5 \%$ & $37,3 \%$ & $26,8 \%$ & $54,1 \%$ \\
\hline & Este - Alcosa - Torreblanca & $24,6 \%$ & $38,3 \%$ & $23,1 \%$ & $46,9 \%$ \\
\hline & Triana & $23,9 \%$ & $33,4 \%$ & $17,2 \%$ & $38,6 \%$ \\
\hline & Palmera - Bellavista & $22,3 \%$ & $31,2 \%$ & $18,5 \%$ & $34,7 \%$ \\
\hline & Casco Antiguo & $21,2 \%$ & $28,7 \%$ & $15,6 \%$ & $27,3 \%$ \\
\hline & Sur & $21,1 \%$ & $37,0 \%$ & $15,6 \%$ & $44,7 \%$ \\
\hline & Nervión & $19,3 \%$ & $30,6 \%$ & $11,6 \%$ & $23,4 \%$ \\
\hline & Remedios & $18,2 \%$ & $32,9 \%$ & $12,6 \%$ & $44,6 \%$ \\
\hline
\end{tabular}

* según la denominación del Mapa de Vivienda Gitana

Fuente: Resultados de elecciones, Ministerio del Interior y Atlas de distribución de la renta de los hogares (INE, 2019) 
HUELVA

De los 4 candidatos de etnia gitana que se mencionaban anteriormente elegidos como diputados en las elecciones generales de abril de 2019, el único de ellos al que se le ha encontrado una vinculación directa con algún barrio estudiado es a Juan Antonio Cortés, elegido diputado con una fuerte exposición mediática, y que según los medios es residente en el barrio El Torrejón de Huelva, uno de los estudiados. Por tanto, cabría preguntarse si el hecho de que se presentara como diputado una persona muy conocida en el barrio y en general en España por su alta presencia en televisión ha hecho aumentar la participación en el mismo.

El barrio del Torrejón, como se puede ver en el gráfico 9, es uno de los barrios que acumula un mayor porcentaje de población pobre y también es uno de los de mayor abstención. Es de hecho el único clasificado como de concentración alta de gitanos en Huelva.

Gráfico 9: Gráfico de dispersión de secciones de Huelva por porcentaje de hogares en riesgo de pobreza y abstención promedio 2015-2019

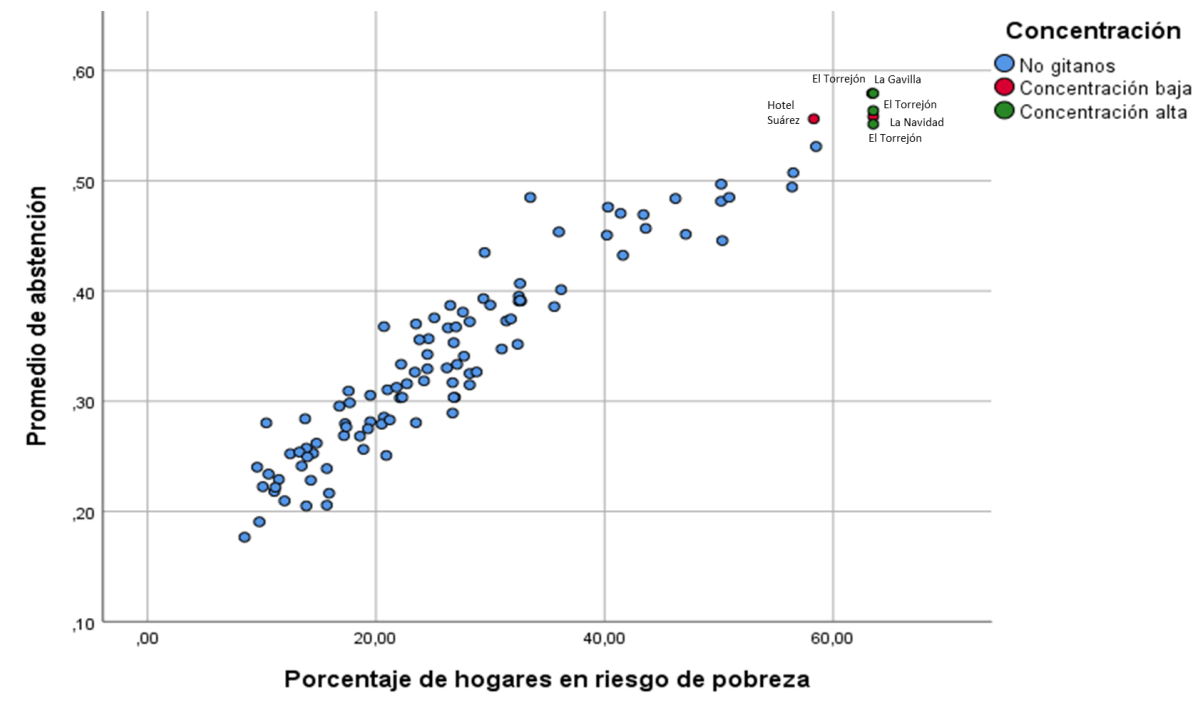

Fuente: Resultados de elecciones, Ministerio del Interior y Atlas de distribución de la renta de los hogares (INE, 2019)

Los otros BCPG de Huelva, La Gavilla, La Navidad y Hotel Suárez, comparten los datos de alta abstención y alto porcentaje de pobreza, como se puede ver en la tabla 15, muy superiores al resto de barrios de los distintos distritos. 
En esta misma tabla vemos como los niveles de abstención en el barrio del Torrejón no bajan de forma importante, de hecho, la abstención baja menos que en otros barrios con respecto a las elecciones de 2016. Podemos concluir por tanto que, al menos en este caso, y sin que ello se pueda generalizar, el presentarse un candidato gitano no ha provocado una disminución de la abstención en su barrio.

Tabla 15: Abstención y Porcentaje de hogares en riesgo de pobreza por distritos y barrios gitanos en Huelva

\begin{tabular}{|l|c|c|c|c|c|}
\hline \multirow{2}{*}{ Barrio* } & \multirow{2}{*}{$\begin{array}{c}\text { Distrito (servicios } \\
\text { sociales) }\end{array}$} & \multirow{2}{*}{$\begin{array}{c}\% \text { de } \\
\text { pobreza }\end{array}$} & \multicolumn{3}{|c|}{$\%$ de abstención } \\
\cline { 4 - 6 } & V & $63,5 \%$ & $54,6 \%$ & $58,1 \%$ & $56,7 \%$ \\
\hline El Torrejón & III & $58,3 \%$ & $55,1 \%$ & $58,7 \%$ & $53,1 \%$ \\
\hline Hotel Suárez & III & $63,4 \%$ & $56,0 \%$ & $62,2 \%$ & $55,5 \%$ \\
\hline La Gavilla & III & $63,5 \%$ & $55,3 \%$ & $56,6 \%$ & $55,6 \%$ \\
\hline La Navidad & I & $14,8 \%$ & $25,1 \%$ & $26,2 \%$ & $21,9 \%$ \\
\hline \multirow{3}{*}{$\begin{array}{l}\text { Barrios sin } \\
\text { presencia gitana }\end{array}$} & II & $25,7 \%$ & $33,7 \%$ & $35,3 \%$ & $30,8 \%$ \\
\cline { 2 - 6 } & III & $37,9 \%$ & $41,6 \%$ & $44,8 \%$ & $40,4 \%$ \\
\cline { 2 - 6 } & IV & $32,7 \%$ & $39,7 \%$ & $42,9 \%$ & $37,6 \%$ \\
\cline { 2 - 6 } & V & $33,7 \%$ & $39,7 \%$ & $42,2 \%$ & $37,2 \%$ \\
\cline { 2 - 6 } & VI & $31,6 \%$ & $36,6 \%$ & $39,8 \%$ & $35,3 \%$ \\
\hline
\end{tabular}

* según la denominación del Mapa de Vivienda Gitana

Fuente: Resultados de elecciones, Ministerio del Interior y Atlas de distribución de la renta de los hogares (INE, 2019)

\section{CONCLUSIONES}

La abstención electoral afecta de manera desigual a los grupos sociales (Weeks 2014). Aunque el voto es el mecanismo de participación política más igualitario, el que consigue la participación de mayor porcentaje de personas, deja de serlo si algunos grupos de la sociedad quedan sistemáticamente excluidos del mismo. La participación electoral debe ser un mecanismo que ayude a corregir las desigualdades socioeconómicas. Pero si un grupo social participa en menor medida que el resto, sus preferencias políticas no son introducidas en el sistema a través del voto (McElwee 2015). 
En este artículo, aplicado al caso de la comunidad gitana, hemos visto los problemas que existen al analizar la desigualdad en la participación política con datos de encuesta. $\mathrm{Al}$ analizar la relación entre pobreza y participación con datos de sección censal es posible, en cambio, tener un mayor detalle geográfico y utilizar variables limpias que nos ofrecen una clara relación.

Se ha puesto de manifiesto que en los barrios donde está concentrada la población gitana la participación en elecciones generales es considerablemente menor que en el resto, y que ello ocurre de forma generalizada. Sin embargo, este dato hay que relativizarlo, teniendo en cuenta las características de las personas que habitan estos barrios. En estos barrios se dan los niveles más bajos de renta. Son barrios donde hay un alto grado de exclusión social. Cuando se introduce este factor, se encuentra que la mayor parte de la falta de participación política puede ser explicada por el bajo nivel de renta de los barrios con alta concentración de población gitana. Por tanto, podemos concluir que las personas que habitan en barrios con concentración de población gitana participan mucho menos políticamente que el resto de los españoles. Pero que, en buena medida, ello no tiene que ver con el hecho de ser gitanos, sino con el hecho de ser pobres, aunque aún puede quedar un pequeño efecto debido a este hecho.

\section{BIBLIOGRAFIA}

ALHAMBRA, M. Y RUIZ, S. (2017): "Contra el "votante medio". Indicios de desigualdad social y capital político a partir de la abstención electoral y la estructura de voto en Madrid y Barcelona desde el nivel de barrios." Revista Encrucijadas, 13.

BARANY, Z. (2001): "Romani electoral politics and behaviour." JEMIE - Journal on ethnopolitics and minority issues in Europe, 1, pp. 1-12.

BERMÚDEZ, S. Y FERRER FONS, M. (2014): “Abstencionismo y movilización electoral en las elecciones autonómicas del periodo 2009-2012”, en Elecciones autonómicas 2009-2012, editado por F. Pallarés. CIS, Madrid, pp. 187-300.

BLAIS, A. (2000): To vote or not to vote?: The merits and limits of rational choice theory, Pittsburgh, University of Pittsburgh Press.

CAMARILLO, J.M. Y SÁNCHEZ, F.J. (2018): "Abstenerse es cosa de pobres". Andalucía Información, 12 de diciembre. Consultado: 10 de febrero de 2020

CAINZOS, M. (2001): "La evolución del voto clasista en España, 1986-2000". Zona Abierta, 96-97, pp. 91-172. 
CAINZOS, M. Y VOCES C. (2014): "En España, estar en paro no cambia el voto, pero aumenta la abstención”. Zoom politico, 21. Fundación Alternativas. Madrid.

DAMONTI, P. Y ARZA PORRAS, J. (2014): "Exclusión en la comunidad gitana". Documento de trabajo 3.5. VII Informe sobre exclusión y desarrollo social en España. Fundación Foessa. Madrid.

DE LA FLOR TORRE, A.M. (1997): "Participación política". O Tchatchipen, 20, pp. 38-39.

EMPRESA MUNICIPAL DE VIVIENDA Y SUELO (2017): "Listado de viviendas propiedad de la EMVS". Consulta en 15 de septiembre de 2019 (https://www.datanalytics.com/wpuploads/2017/05/listado_bienes_EMVS.docx)

EUROPA PRESS (2019): "La comunidad gitana logra una representación histórica en el Congreso". Europa Press, 29 de abril. Consultado en 10 de febrero de 2020 ( https://www.europapress.es/epsocial/igualdad/noticiacongreso-contara-mayor-representacion-comunidad-gitana-historia-cuatrodiputados-20190429134448.html)

EUROPEAN UNION AGENCY FOR FUNDAMENTAL RIGTHS (2016): "Segunda encuesta de la Unión Europea sobre las minorías y la discriminación. La población romaní: resultados principales.". Consulta: 12 de septiembre de 2019 (https://www.gitanos.org/upload/99/80/fra-2016-euminorities-survey-roma-selected-findings_es.pdf)

FUNDACIÓN SECRETARIADO GITANO Y DALEPH (2016): "Estudio-mapa sobre vivienda y población gitana, 2015. Ministerio de Sanidad, Consumo y Bienestar Social.". Consulta: 15 de junio de 2019

FUNDACIÓN SECRETARIADO GITANO (2019): "Estudio comparado sobre la situación de la población gitana en España en relación al empleo y la pobreza 2018". Consulta: 10 de enero de 2020. (http://www.gitanos.org)

GALLEGO, A. (2007): “Unequal Political Participation in Europe”, International Journal of Sociology, 37-4, pp. 10-25

GALLEGO, A. (2010): "Understanding unequal turnout: Education and voting in comparative perspective”. Electoral Studies 29, pp. 239-248

GALLEGO, A. (2013): “¿Votan más los ricos que los pobres? En España, no”. Eldiario.es. Piedras de Papel. 24 de julio. Consulta: 15 de enero de 2020 
(https://www.eldiario.es/piedrasdepapel/Votan-ricos-pobres-Espana 6 156844322.html)

GÓMEZ FORTES, B. Y TRUJILLO CARMONA, M. (2011): "Los excluidos también pueden votar: abstención y exclusión social en España". Documento de trabajo. Fundación Alternativas, Consulta en 6 de junio de 2019 (http://www.fundacionalternativas.org/public/storage/laboratorio_document os_archivos/9e6dac56e9cee014470e9b9ac73e2c31.pdf)

GÓMEZ FORTES, B. Y TRUJILLO CARMONA, M. (2016): "Urnas vacías en los suburbios de las ciudades". Observatorio Social de La Caixa. Consulta: 15 de mayo de 2019 (https://observatoriosociallacaixa.org/-/urnas-vacias-suburbiosciudades)

HERNÁNDEZ-PEDREÑO, M., GEHRING, R. Y GARCÍA-LUQUE, O. (2019): "Situación social de la población gitana en España: balance tras la crisis". Documento de trabajo 3.12. VIII Informe FOESSA. Consulta: 12 de febrero de 2020

(https://caritas-web.s3.amazonaws.com/main-files/uploads/sites/16/2019/06/3.12.pdf)

INSTITUTO NACIONAL DE ESTADISTICA (2019): "Atlas de distribución de renta de los hogares. Proyecto técnico". Consulta: 5 de febrero de 2020 (https://www.ine.es/experimental/atlas/exp_atlas_proyecto.pdf)

LIJPHART, A. (1997): “Unequal Participation: Democracy's Unresolved Dilemma”, American Political Science Review 91, pp. 1-14.

LLANERAS, K. Y CARRETERO, N. (2019): “De espaldas a las urnas”. El Pais, 28 de marzo. Consulta: 15 de febrero de 2020

(https://elpais.com/politica/2019/03/28/actualidad/1553783809_455746.html)

MAHLER, V., JESUIT, D. Y PARADOWSKI, P. (2014): "Electoral Turnout and State Redistribution A Cross-National Study of Fourteen Developed Countries", Political Research Quaterly, 67-2.

MAKKONEN, T. (2016): "European handbook on equality data". European Commission. Brussels. Directorate-General for Justice and Consumers.

MCELWEE, S. (2015): "Why voting matters". Demos. Consulta: 15 de septiembre de 2019

(https://www.demos.org/sites/default/files/publications/Why\%20Voting\%20Mat ters $0 . p d f$ ) 
MÉNDEZ, C. (2005): "Por el camino de la participación. Una aproximación contrastada a los procesos de integración social y política de los gitanos y las gitanas", Tesis doctoral, Departament d'Antropologia Social i Cultural, Universitat Autonoma de Barcelona, Barcelona, España.

PALLARÉS, F., FRAILE, M. Y RIBA, C. (2007): "Variables socioestructurales y comportamiento electoral en las elecciones generales españolas. Una perspectiva evolutiva 1979-200". Revista de Estudios Políticos, 135, pp. 109158.

REUSS, A. Y MACK, J. (2019): "Data collection on equality, discrimination and antigypsyism”. En I. Cortés Gómez y M. End, Dimensions of antigypsyism in Europe. Central Cousin of German Sinti \& Roma. Brussels.

RIBA, C. Y BOIX, C. (2000): "Las bases sociales y políticas de la abstención en las elecciones generales españolas". Revista Española de Investigaciones Sociológicas 90, pp. 95-130.

SAN ROMÁN, T. (1997): "El desarrollo de la conciencia política de los Gitanos. Pensamiento y Cultura". Gitanos: Pensamiento y Cultura 0, pp. 36-41.

SÁNCHEZ, R. (2019): "Por qué los barrios pobres no van a votar: la abstención en las zonas más excluidas duplica a la de las más ricas”. Eldiario.es 7 de abril. Consulta: 10 de abril de 2019 (https://www.eldiario.es/politica/barriospobres-van-votar-elecciones_0_884011872.html)

TRUJILLO CARMONA, M. Y GÓMEZ FORTES, B. (2019): "La segregación electoral interurbana en España. Relación entre participación y renta". Documento de trabajo 3.4. VIII Informe FOESSA. Fundación FOESSA, Madrid. Consulta: 18 de octubre de 2019 (https://caritasweb.s3.amazonaws.com/main-files/uploads/sites/16/2019/05/3.4.pdf).

WEEKS, D. (2014): "Why Are the Poor and Minorities Less Likely to Vote?" The Atlantic, 10 de enero. Consulta: 30 de marzo de 2020 (https://www.theatlantic.com/politics/archive/2014/01/why-are-the-poorand-minorities-less-likely-to-vote/282896/)

WHITELEY, P., CLARKE, H., SANDERS, D, Y STEWART, M. (2001): “Turnout". Parliamentary Affairs, 54, pp. 775-88. 
Recibido: 10 de septiembre de 2019

Aceptado: 15 de octubre de 2019

Manuel Trujillo Carmona es Licenciado en Matemáticas, Especialidad Estadística e Investigación Operativa, Universidad de Granada. Técnico Superior en el Instituto de Estudios Sociales de Andalucía (IESA-CSIC). Responsable de diseño muestral en dicho instituto desde 1997. Co-autor de numerosos estudios sobre pobreza, exclusión socias, como el plasmado en el libro "Pobreza y Exclusión Social en Andalucía" (2003), al que siguieron otros similares en Asturias, Cantabria y Aragón. Posteriormente fue coautor de los primeros estudios en España donde se relacionaba la abstención electoral con la exclusión social, asunto ahora muy comentado, como "Los excluidos también pueden votar: abstención y exclusión social en España” (2011), o "Urnas vacías en los suburbios de las ciudades" (2016). Colabora desde 2006 en el diseño y muestreo de las encuestas FOESSA (publicadas en los informes 2008, 2013 y 2019), y también ha participado en el "Estudio del Secretariado Gitano sobre la situación de la población gitana en relación al empleo" (2019). 